BRTTISH MEDICAL JOCRNAL VOLUME $287 \quad 3$ DECEMBER 1983 PRACTICE OBSERVED

\section{Practice Research}

\section{Entry to general practice training}

JAMES ROBERTS, JAMES FREEMAN

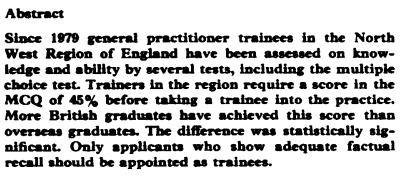

Introduction

The purpose of mandatory training for general practice is to
raise the level of practice in Britain. The training is taid down in terms of experience offered by hospitial and general practice
trainers and not in terms of benefit gained by the crainee.
Once a trainee has satisfactorily completed training a cerrificate

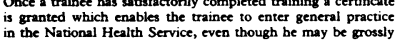
incompetent
For some ears trainers in the north west of England have
realised that some applicants for traince posts do not have a standard of fartual Irecall of chinical matrers sufficiently high
for them to benefit from the trainee year. In any educational for them to benefit from the trainee year. (In any educational
exercise at the advanced or higher levels participants must have

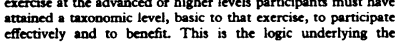

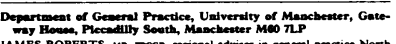

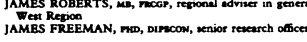

concept of all minimum course requirements implemented in
most institutions of higher education.) The out such besic deficiencies, to the possible detriment of partients in the practice when the applicant was appointed.
Trainees in the day release courses have expressed concern Traineses in the day recease courses have expressed concern
that visiting speakers are occasionally asked a uestions by mem-
bers of their groups on marters that should be assumed to be
undergraduate common knowiedge and that such questions

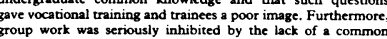
group work was seriously inhibited by the lack of 2 cormmon
basis of clinical factual recall from which hinteligent discussion hopelessness was engendered at the low degree of achieverent
in thess sessions. Since September 1979 , therefore, the trainers
in the region have agreed that they will not accept as rrainees applicants who are not in vocational schemes who cannot show that they have reached a specific level of adequate recall of
clinical facts. Trainees in vocational schemes are selected out by other means and carlier in their trainining. They nourmally
voluntarily undergo the assessment with universally good A system has been set up whereby the trainec applicant, as
part of a pre-employment interview, completes a multiple hoice test that covers the specialties experienced in genera

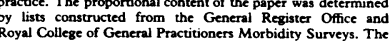
Royal Callege of General Practitioners Morbidity Surveys. The
test has 220 questions-36 psychiatry, 40 paediatrics and infectious disecesess, 40 medical, 24 thererapeutics, 24 obstetrics
and gynaecology, 16 ear, nose, and throat, and ophthalmics and a correct answer from a group of five choices. The paper is personally administered and supervised, explang-
tion and reassurance are therefore at hand, and the applicant is allowed whatever time is necessary to answert the questions.

\section{8

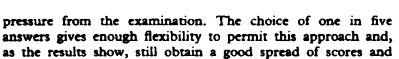

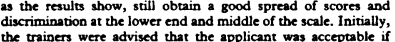

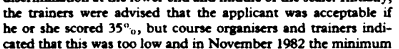

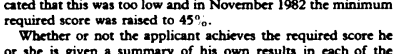

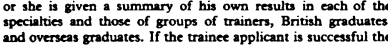

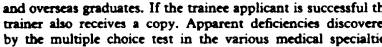

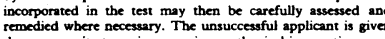

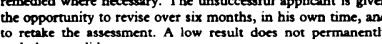

Resulta and dilecussion

Of 602 candidates who undertook the assessment, 110 scored
wder $45^{\circ}$. At the other end of the scale there were 75 who

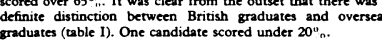

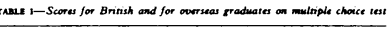

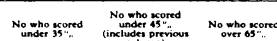

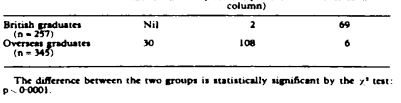

The term "British graduate" includes only graduates of the
niversities of Great Britian, excluding Eire, irrespective of

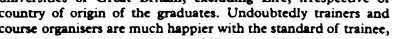
although course organisers would like to see the required score

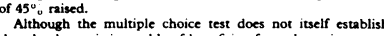

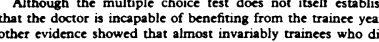

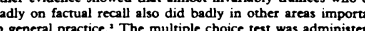

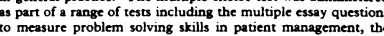

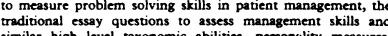

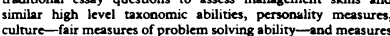

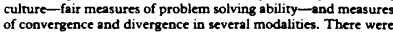
high correlations among these mesaures, particularly at he
lowerer end of the scale. The multiple choice ters tended to have

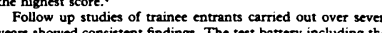

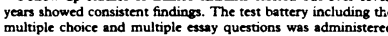

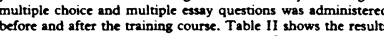

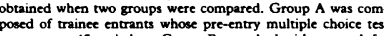

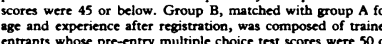

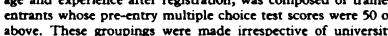

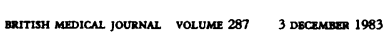

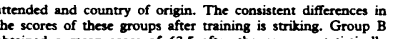

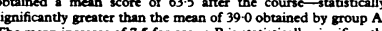

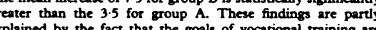

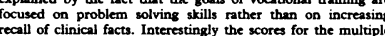

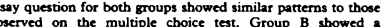

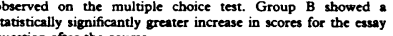

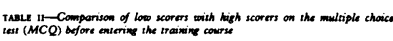

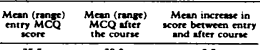

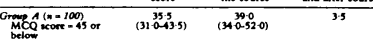

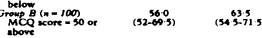

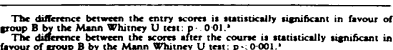

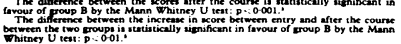

The multiple choice questions were chosen to reffect the
range and the appropriate depth of knowledge for general

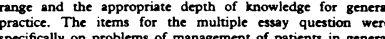

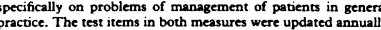

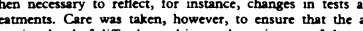
propriatc level of difficulty and interenal consistrency of the ters

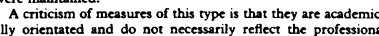

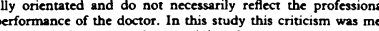

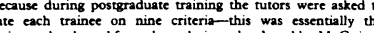
The critertia used on the rating scale were: $(a)$ information

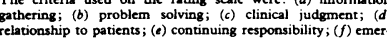

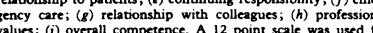

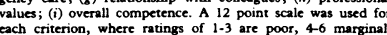

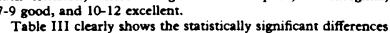

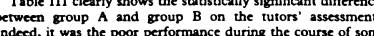
Indede, it wass he poor performance during the course of som
traines in this group that movivated maxing these assessments

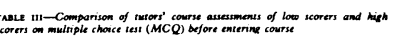

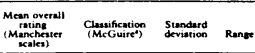

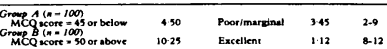

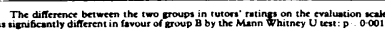

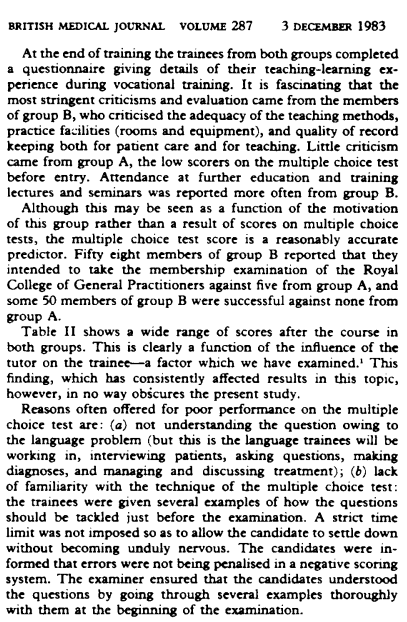

Research has shown that if extra time is allowed the overall
core improves. The success of this is shown by the fact that

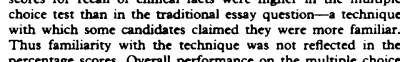
test in terms of relative scores was invariably betrer than
performance on the multiple essay question, the traditional

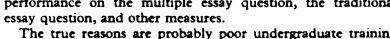

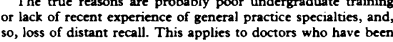

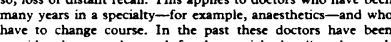
for revision and training before the trainee year. To safeguard the future of general practice all applicants for trainee posts in
general practice should be required to show themselyes capabte of benefiting from the trainee year before entering on that year.

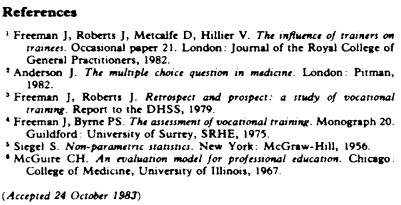

\title{
Do trainees see patients with chronic illness?
}

JOHN C HASLER

Abotract

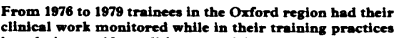

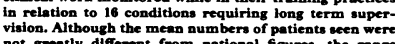
not greatly different from nationel figures, the range:
identified some trainees whose number of patients wat

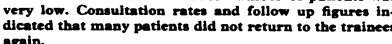

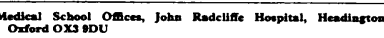

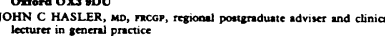

Vocational training for general practice has been in operation for
well over a 2 deacese, and in 1982 a three year posstregistration mandatory for those doctors wishing there have been many papers on the eductional aspects of train-

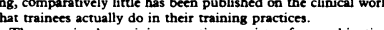

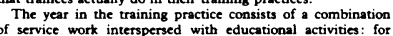
moss, if not all, trimes revice wert occupies mosst of the time

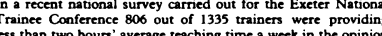

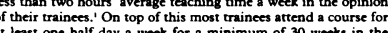
at leass one half day a weck for a minimum of 30 wects in the

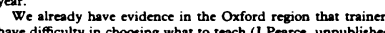

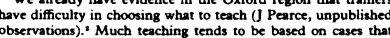

160

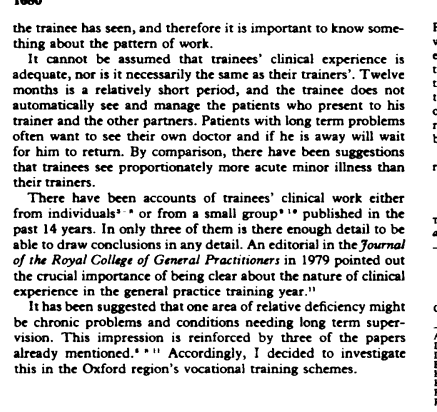
3 DeCCMBRER 1983

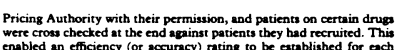

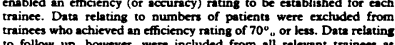

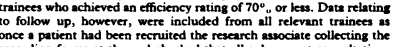

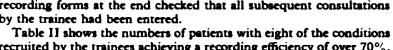

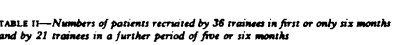

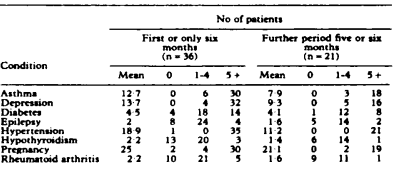
Study

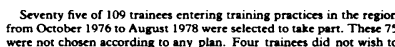

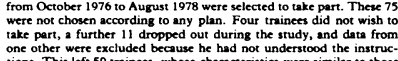

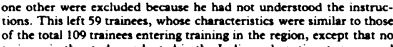

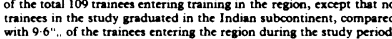

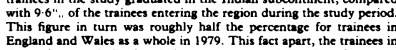

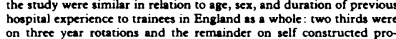

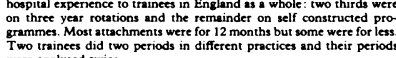

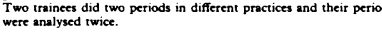

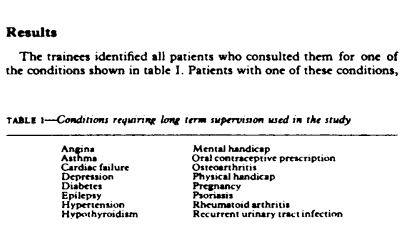

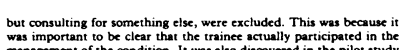

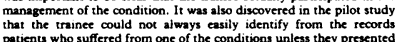

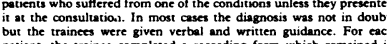

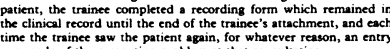

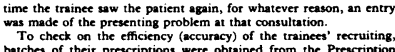
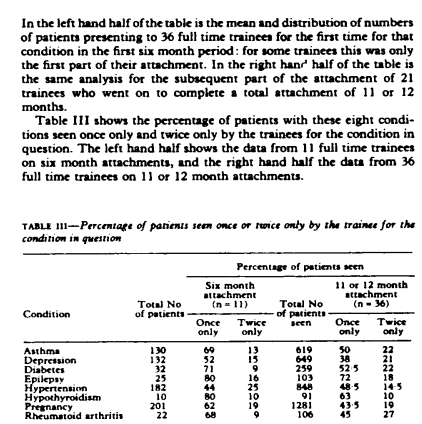

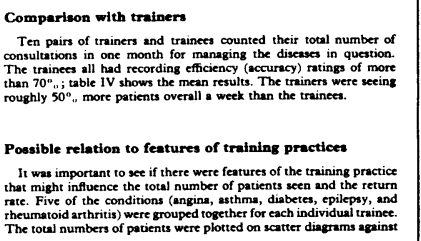




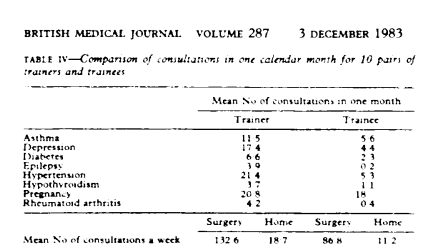

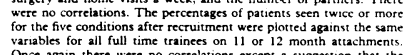

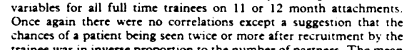

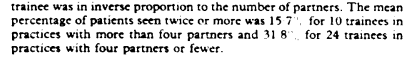

Prescribing

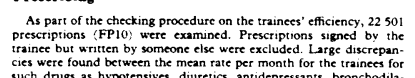

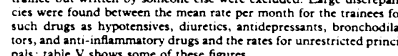

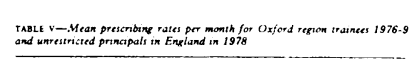

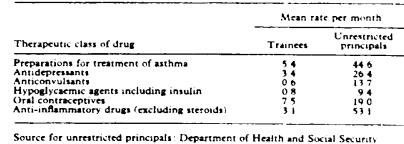

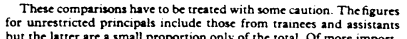

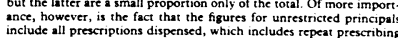

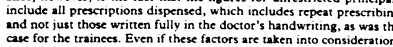

Discussion

It may be seen that most patients with these chronic problem
that each trainee managed consulted him in the first six months
Table II shows that the mean number of patiens

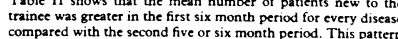
compared with the second five or six month period. This patter
was apparent in virtually every analysis from cach trance for every condition. It seems therefore that the trainees did not have
to be essablished in the practice for several months before these
patients came to consult them. the practice mean list size of each principal, the mean number of traine
The number of patients consulting per 1000n 1681

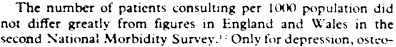

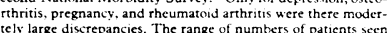
hy the trainces, however. does give rise to some concern.
For 11 out of the 16 condituons there were some trainces on 12

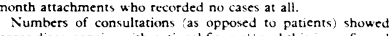

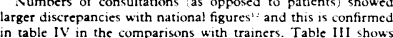

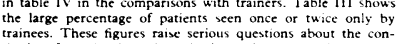

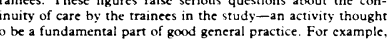

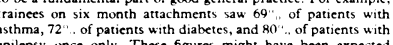
cilepsy vnce only. These figures might have been expected
some extent. But the same cannor be said of depression and

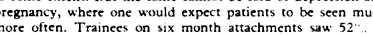

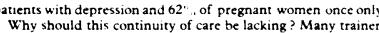

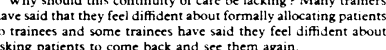

Conclusions

It is clear that the study could not relate what the trainees
saw to how much they leamt. Nor can one deduce that there was standard relation between the two or that there is a certain

condition

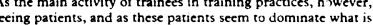

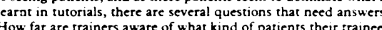

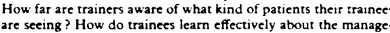
ment of conditions if they have secn no paticnts with the condi-
tion in question? Some kind of clinical log book seems to be Hoed feasible is it to change the trainces' clinical work if it seems that some arcas are deficient? The percentages of patients

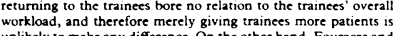
unlikely to make any difference. On the other hand, Fouracre and

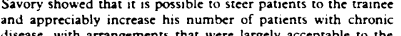
patients.".
What actors infuence how trainess learn and teach in individual consultations to achieve the maximum learning?
in the Oxiord region we have recently completede work on In the Oxiord region we have recently completed work on
identifiving priority obiectives for vocational tranining (unpub-

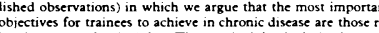
lated vo general principles. These principles indlude those

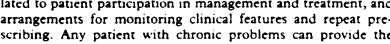

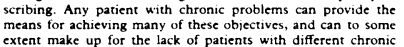
cxtent make up for the lack of patients with different chront
problems
It is to be hoped that the results of this study will highight

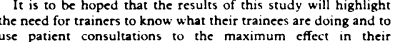
ise patient consultations to the maximum effect in their
leaching. It is a pleasure to thank the trainers and trainces in the Oxford

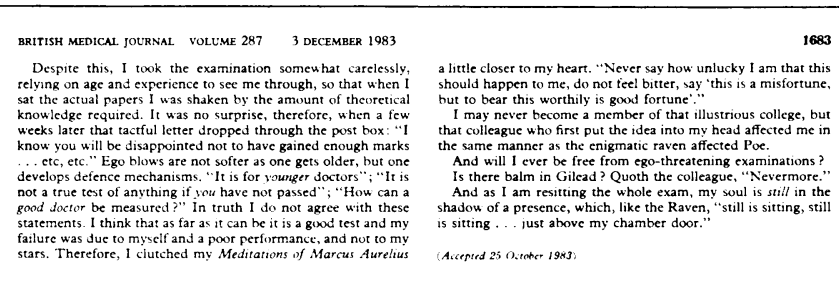

\section{Minimum Standards for Training}

\section{Do standards improve patient care?}

J J C CORMACK

The best government is that which grverns least. J O' Sullivan, 1837.

Of all the maior divisions or specialtites in medcine, general
pracice is probably the most diverse in philosophy, tradition,

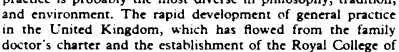
doctor's charter and the establishment of the Royal College of
General

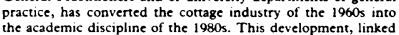

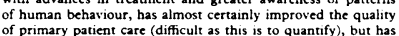
of primary patient care difificult as this is to quannify), but has
it begun to threaten the diversity, which is onc of the gloties of

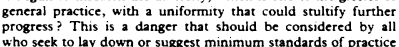
or of training. The establishment of vocational training as a statutory
prerequisict for independent gencral practice places a heavy

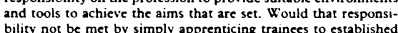
bility not be met by simply apprenticing traineses to established
praccitioners and then letring them fend for themselves? Is it

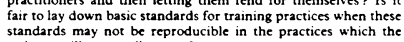
traineses will evenanally enter?
It think that apprenticeship is not enough and that it is fair

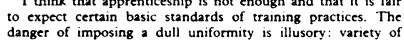

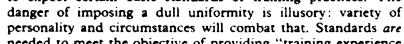

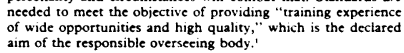

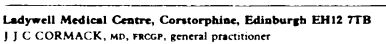

Objective

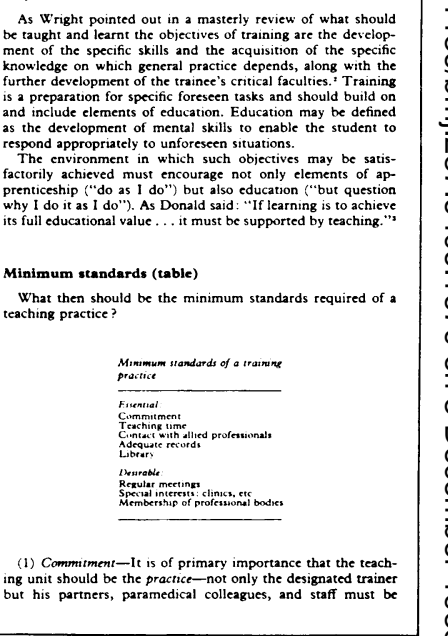

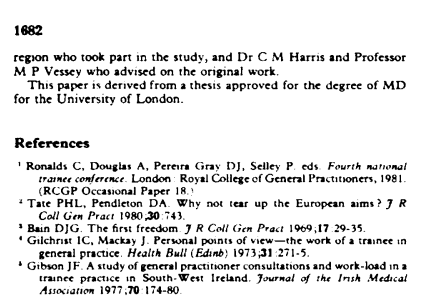

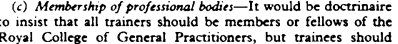
fip in helping to fosser good morale and high standards and
combers

\section{MRCGP Examination}

\section{Do you think, at your age, it is right?}

RAYMOND E GOODMAN

To my shame, no sense of guilt, no fear of being out of date, nor
2ny overwhelminis passion to update myself was sufficient to
cause me to re-read the whole syllabus of medicinc affer a gap of cause me to re-read the whole syllabus of medicinc after a a ap
20 years. I had dabbled, reading the odd journal now and then
bur byt only articles that interesersed me and little outside my special
interests. The ideco of a medical examination after so long awoke me, like Shelley's west Wind did the sleeping Mediterranean
which had been "lulled by the coil of his crystalline streams
Beside a pumice isle in Baia's bay." Since I trook a textbook of meside a pumice isle in Bail's bay." "Since I took a textbook
medicin on holiday with met to that region, the similis eis apt, both
that sea and I "going grey with terror" at our respective impending encounters.
In the past I had always read the classics when revising for finals, so that, although I retook examinations regularly and
many different places, I read the works of Chavcer, Dante. an Gibbon. (Unfortunately, there was never a question on them in
the subsequent papers.) For my recent postemenopausal fasco
with the membership examination of the Royal Coliege of General Practitioners I read volume 1 of Proust's Remembrance
of Things Sast in the new Penguin edition. Proust describes how of Things Past in the new Penguin edition. Proust describes how
falling asleep in 2 strange bed leads him to drift back to carlief
sleeps in other beds, to encounter again those night terrors of sleeps in other beds, to encounter again chose night terrors of
childhood. In the same way becoming a candidate again revived memories of examination horrors for me, those fraught con-
frontacoss that can shatrer the ego so.
In some of my current nightmares am late, I rush across London, only to be told that the exam is in oriental studies, or
ancient Greck, and I awaze sweating . No wonder De Quincy
who himself suffered terrible starvation and poverty in the

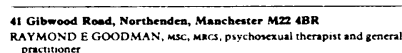

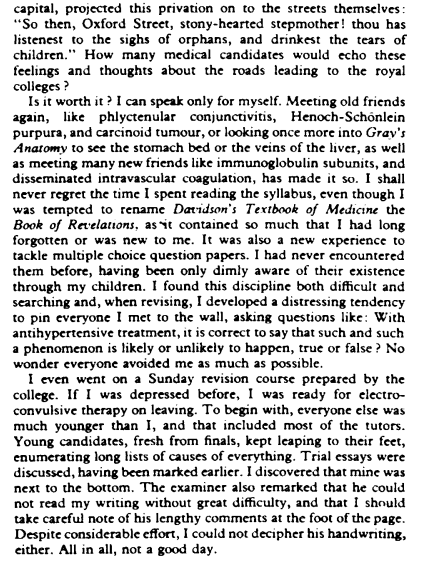

1684

aware of and committed to the ceaching programme. The
trainer may undertake the bulk of the tecaching programme or he may delegate iti he will probably be responsible for the
amministration and intergation of the programmete th ought some

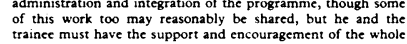

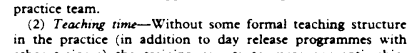

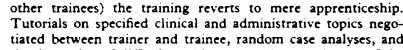

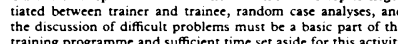

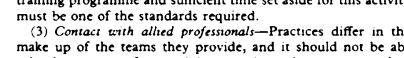

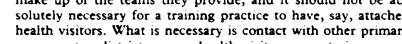

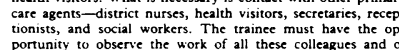

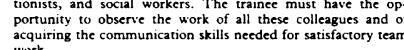

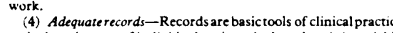

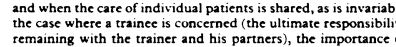

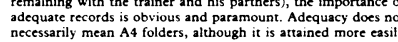

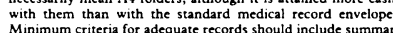

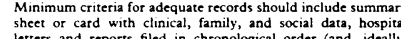

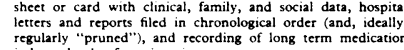

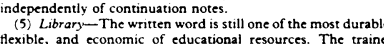

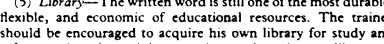

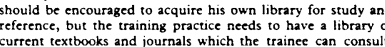

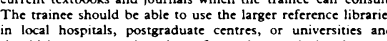

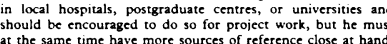

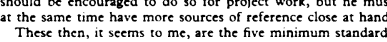

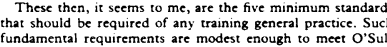
lindmental requirements are mode
livan's call for minimal government.

\section{Other desirable strributes}

There are many other desirable atrributes hat are helpfoul bur

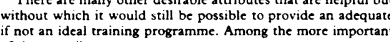

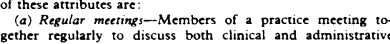

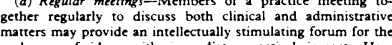

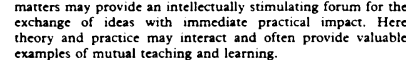

BRTTISH MEDICAL JOURNAL VOLUME $287 \quad 3$ DECEMBER 1983

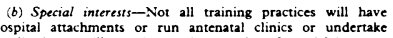

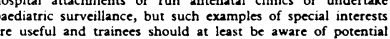

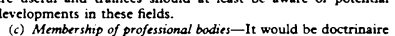

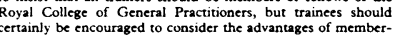

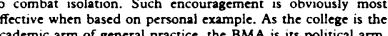
academic arm of general practice, the BMA is its politicial arm,
and all members of the profession who wish to influence (or indeded enioy) negotiated remuneration and conditions of
service should act from within rather than grumble from

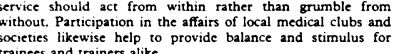

Challenge of trandard setting

Freceling and Fitron recently suggested that all trainces should

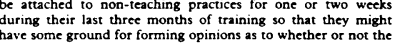

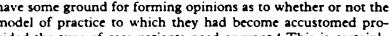

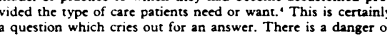

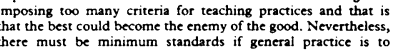
progresess.
The environment of the training general practice cannot be
"all things to all men" and it should be accepted that on completing his trainecthip the crainec as prospective principipal may
oc faced with very different conditions. To meet and work

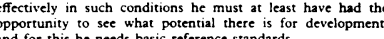
The challenge to the profession, and especially to the ace

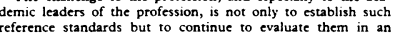

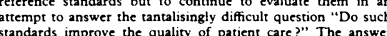

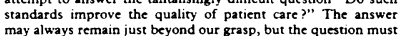

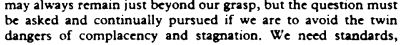
dangers of complacency and stagnation. We need standard
but they muss be capble of iussification.

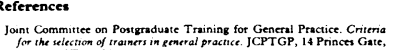

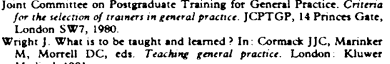

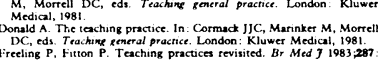

